\title{
Guest editorial: special issue on wind power technologies
}

\author{
Liangzhong YAO $(\bowtie)$
}

Due to global concerns about environmental pollution and potential fossil energy shortage, wind energy has become a significant clean energy for electricity generation systems all over the world. In China the total installed capacity of wind power has been over $70 \mathrm{GW}$ in 2012, which makes China become the country with the largest wind power installation capacity worldwide. According to the official plan of Chinese government, the installed capacity of wind power in China is expected to be 150 and $200 \mathrm{GW}$ in 2015 and 2020, respectively. The report from the Global Wind Energy Council has also shown that the total installed capacity of wind power in the US has reached to $60 \mathrm{GW}$ in 2012. In Europe, the European Commission published its Communication "Investing in the Development of Low Carbon Technologies (SET-Plan)" in October 2009, stating that wind power would be "capable of contributing up to $20 \%$ of EU electricity by 2020 and as much as $33 \%$ by 2030".

However, due to the intermittence and fluctuation of wind, the increasing penetration of wind power into the transmission grid has imposed many technical challenges on maintaining the secure and stable operation and control of transmission grids. In 2011, there were 193 wind power outages occurred in China. Among them, there were 54 outages with wind power losses ranging from 100 to $500 \mathrm{MW}$, and 12 outages with wind power losses over $500 \mathrm{MW}$. Therefore, effective technical solutions associated with the grid integration of large-scale wind power, and safe and reliable operation and control of the transmission grid integrated with large-scale wind power are urgently required.

Received: 8 May 2013/Accepted: 21 May 2013/Published online: 9 July 2013

(C) The Author(s) 2013. This article is published with open access at Springerlink.com

L. YAO, China Electric Power Research Institute, Beijing, China

$(\bowtie)$ e-mail: yaoliangzhong@epri.sgcc.com.cn
This special issue is dedicated to address the challenges, experiences, and solutions for the development of wind power technologies. Eight original research papers are brought together to report the most recent advances in wind power fields, particularly in wind power forecasting, wind turbine driven generation system, wind power integration, modeling and simulation, and operation, control and dispatch of the transmission grid integrated with large-scale wind power, etc. The issue also includes three reviews about the present state of art of research on wind power technologies and the suggestions for promoting the future research in this field.

I would like to take this opportunity to thank all authors who made contributions in preparing their papers, and also thank all reviewers who made their efforts to review and comment each paper. I hope this special issue will be interesting to all readers who work in the field of wind power.

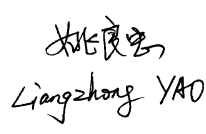

\section{PhD, FIET, SMIEEE}

Vice President

China Electric Power Research Institute

May 23, 2013

Open Access This article is distributed under the terms of the Creative Commons Attribution License which permits any use, distribution, and reproduction in any medium, provided the original author(s) and the source are credited. 